\title{
COMPARISON OF BRACINGS AND SHEAR WALLS AS SEISMIC STRENGTHENING METHODS TO BUILDINGS WITH PLAN IRREGULARITIES
}

\author{
Divyashree $\mathbf{M}^{1}$, Bhavyashree B $\mathbf{N}^{2}$, Gopi Siddappa ${ }^{3}$ \\ ${ }^{1}$ PG Students, Dept. of Civil Engineering, PES College of Engineering, Mandya, Karnataka, India \\ ${ }^{2} P G$ Students, Dept. of Civil Engineering, PES College of Engineering, Mandya, Karnataka, India \\ ${ }^{3}$ Professor \& Head, Dept. of Civil Engineering, PES College of Engineering, Mandya, Karnataka, India
}

\begin{abstract}
Failure of reinforced concrete structures during the past earthquakes has taught us the importance of evaluation of the seismic capacity of the existing buildings. Presence of irregularities is considered as a major deficiency in the seismic behavior of structures. One such forms of irregularity is the presence of re-entrant corners which causes stress concentration due to sudden changes in stiffness and torsion in the buildings due to plan asymmetry. Strengthening the notch of the re-entrant cornered buildings is very essential to ensure a good seismic performance of such buildings. Introduction of bracings and stiff shear walls are the popular methods of strengthening the buildings against their poor seismic performance. This paper aims at comparing the efficiency of these two methods of strengthening of irregular buildings. For this purpose, eight storey buildings are modeled and analyzed by response spectrum and pushover analysis methods using ETABS software. Analysis is carried out for different configurations of bracings and shear walls as strengthening elements with varying stiffness. Results of the analysis confirm the reduction in roof top displacement with the increase in the stiffness of the strengthening elements. Further, for a similar performance level the efficiency and economy of both strengthening methods are compared using a cost comparison analysis. Results of the analysis have showed that shear walls prove to be more economical compared to bracings for a given performance level.
\end{abstract}

Keywords: Pushover Analysis, Re-entrant corners, Response Spectrum, Storey Drifts.

\section{INTRODUCTION}

Behavior of a structure during an earthquake critically depends on its geometry and overall configuration. Buildings with simple and regular configuration perform much better in the event of an earthquake compared to buildings with irregular configurations. Sudden changes in structural stiffness are not desirable for seismic resistant buildings. Many building codes related to seismic analysis and design of buildings recognizes the various types and amount of irregularities and recommends them to be avoided or to adopt advanced method of analysis in order to counteract the effect of such irregularities on the global behavior of the building[1].

Presence of re-entrant corners is one such irregularity which adversely affects the seismic behavior of the buildings [2] But, building systems with re-entrant corners (such as buildings with $\mathrm{L}$ or $\mathrm{U}$ shaped configuration in plan) cannot be avoided as they provide functional superiority. They offer many rooms aligned along the perimeter of buildings with good access to air and light. Hence, re-entrant cornered buildings are mostly employed for school and hotel buildings.
Various configurations of buildings with re-entrant corners are as shown in Fig-1. These types of buildings are severely susceptible for damages during an earthquake. Evidences of poor performance of buildings with re-entrant corners can be seen in many of the past earthquakes (Fig-2).

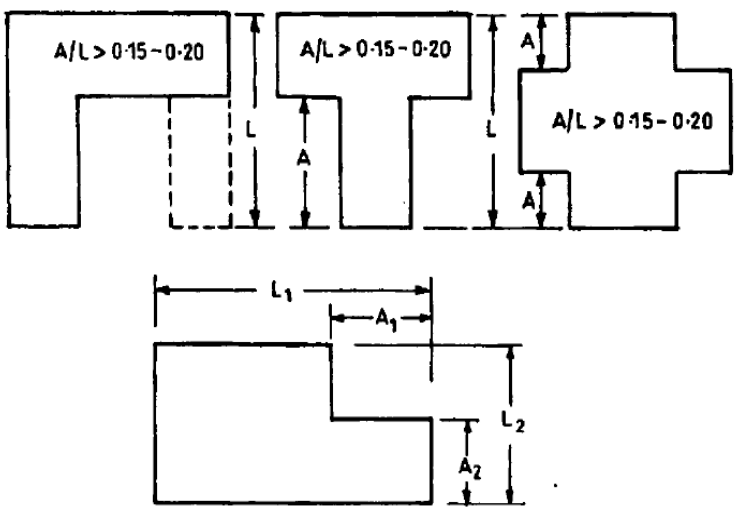

Fig-1: Re-entrant corners as Defined by IS1893:2002 


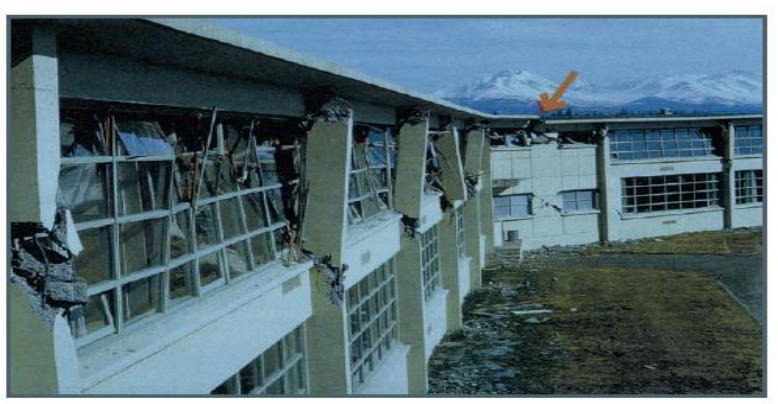

Fig-2: Damages Caused to the Roof Diaphragm at the Reentrant Corner of West Anchorage High School, Alaska. during the 1964 earthquake

\section{SEISMIC BEHAVIOR OF BUILDINGS WITH RE-ENTRANT CORNRES}

The poor seismic performance of buildings with re-entrant corners can be attributed to two things. The first is that they tend to produce differential motions between different wings of the building that result in local stress concentrations at the re-entrant corner or "notch." The second problem of this form is torsion which is caused because the center of mass and the center of rigidity that cannot geometrically coincide for all possible earthquake directions, the result of which is rotation of the building. The resulting forces are very difficult to analyze and predict. The stress concentration at the "notch" and the torsional effects are interrelated.

The magnitude of the forces and the severity of the problems will depend on:

- The characteristics of the ground motion

- The mass of the building

- The type of structural systems

- The length of the wings and their aspect ratios (length to width proportion)

- The height of the wings and their height/depth ratios

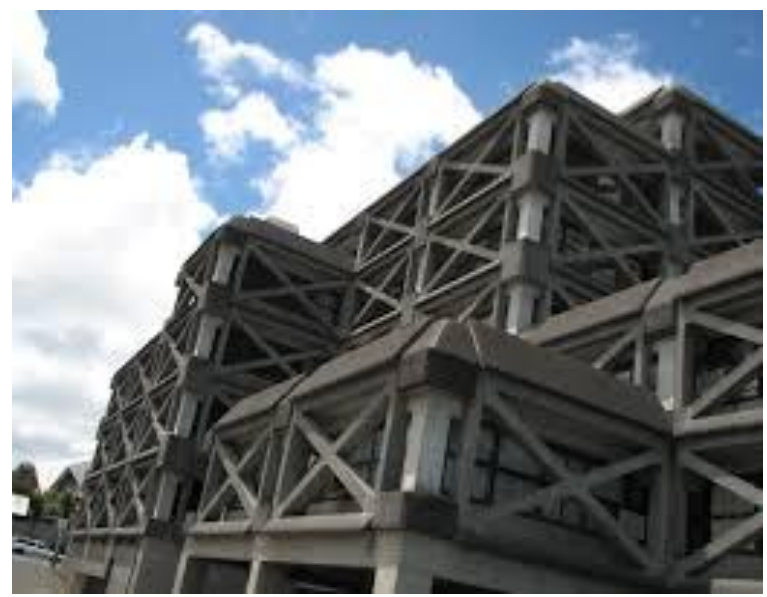

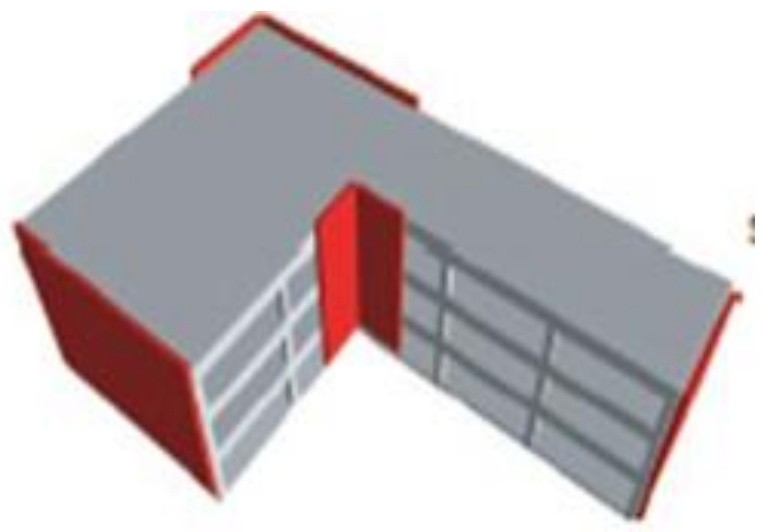

Fig-3: Buildings with Re-entrant Corners Strengthened with Bracings and Shear Walls

The method of relieving these structures from the overstress due to seismic forces by isolating them into simpler and regular configuration buildings may not always be functionally viable. Hence one needs to look at other strengthening methods such as provision of bracings and stiff elements such as shear walls at critical locations to improve the seismic performance of walls (Fig-3).

\section{MODELING AND ANALYSIS}

In the present study, an 8-storey building is modeled and analyzed using the finite element analysis package ETABS [3]. Frame elements consist of columns of dimensions $300 \mathrm{mmx} 750 \mathrm{~mm}$ and beams of dimensions 300mmx450mm. Frame elements are made of concrete of grade M20 and steel of grade $\mathrm{Fe} 415$. The design dead and live loads from the tributary slab areas are applied as uniformly distributed loads on beams.

Earthquake analysis in the form of response spectrum analysis as per IS1983:2002 [1] and pushover analysis as per ATC 40 [4] are carried out using ETABS software. The storey drifts at various floors are determined from response spectrum analysis. For pushover analysis, default hinge properties are used (M3 hinges for beams and PMM hinges for columns) and loads are applied as uniform accelerations in lateral directions.

\section{RESULTS AND DISCUSSIONS}

Typical plan view of ETABS models for regular buildings and buildings with reentrant corners are as shown in Fig-4. 

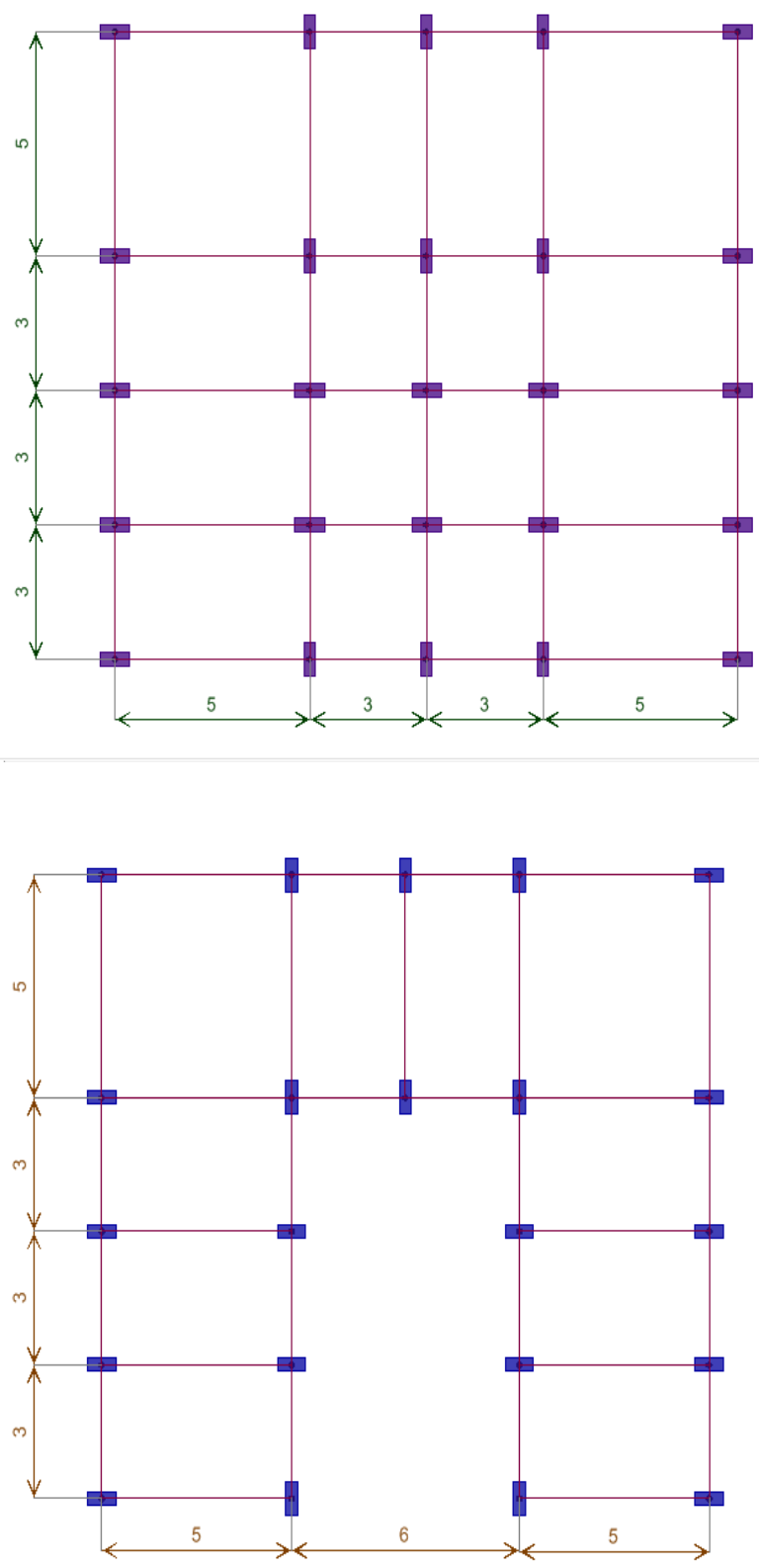

Fig-4: Plan View of Regular and Irregular Buildings

The result of pushover analysis in the form of base shears versus roof top displacement curve and storey drifts from response spectrum analysis are shown in Fig-5 and Fig-6 respectively. From pushover analysis it is evident that regular building has a much higher base shear carrying capacity compared to building with re-entrant corners. Also, from response spectrum analysis it can be seen that buildings with reentrant corners under go much higher storey drifts compared to building with regular configuration.

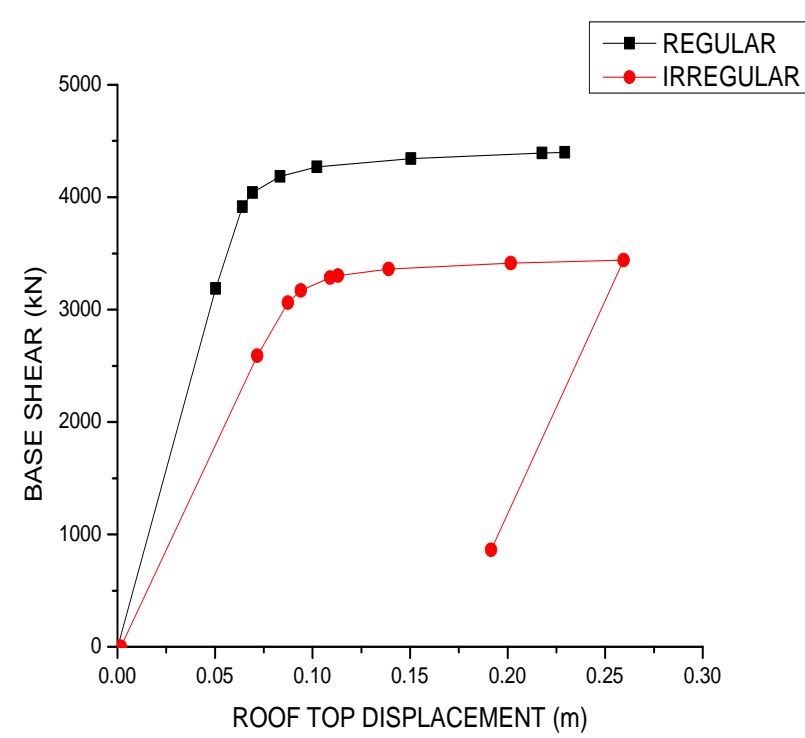

Fig-5: Pushover Curve for Regular and Irregular Buildings

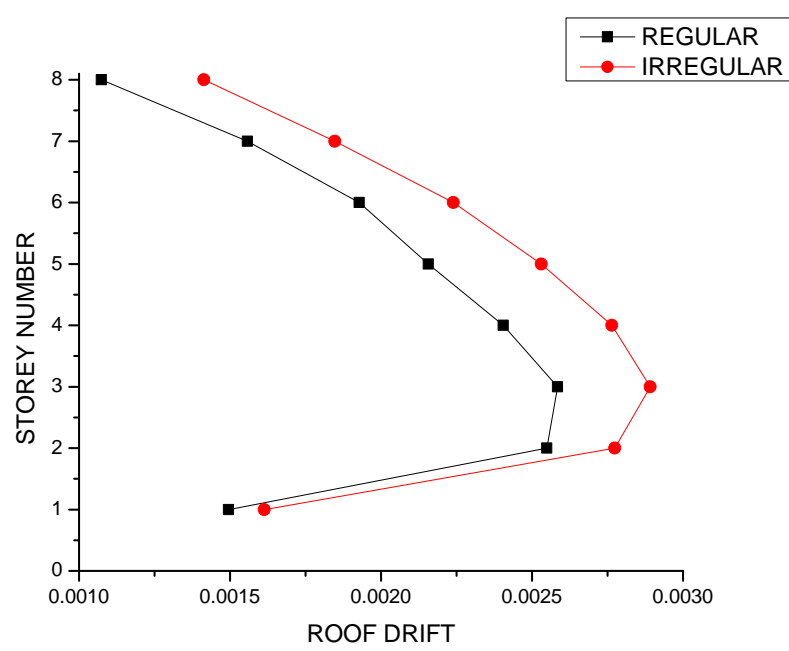

Fig-6: Storey Drifts for Regular and Irregular Buildings from Response Spectrum Analysis

The status of hinges formed at failure during pushover analysis is as in Fig-7. A review hinge formation reveals the stress concentration at the notches of a reentrant building. Hence, notches are the portions of a building with re-entrant corners that are vulnerable for failure during an earthquake due to stress concentration and should be suitably strengthened. 


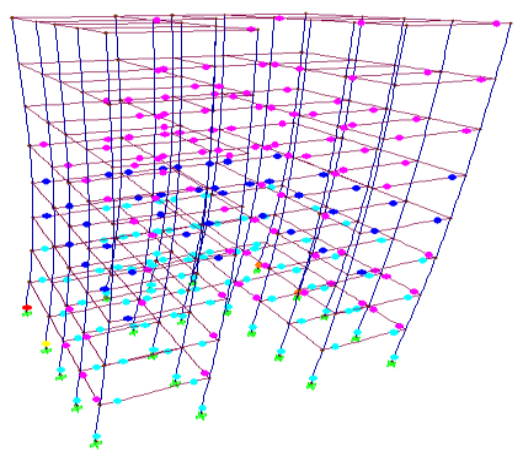

Fig-7: Status of Hinge Formation at Failure

\subsection{Strengthening of the Buildings with Shear Walls}

Fig-8 shows the re-entrant cornered buildings strengthened with shear walls. Two different cases of strengthening, in which inner and outer notches of the building are strengthened with shear wall of $100 \mathrm{~mm}$ thickness, are considered. Shear walls are of the same grade of materials as that of the frame elements and provided with reinforcements as per the design requirements.
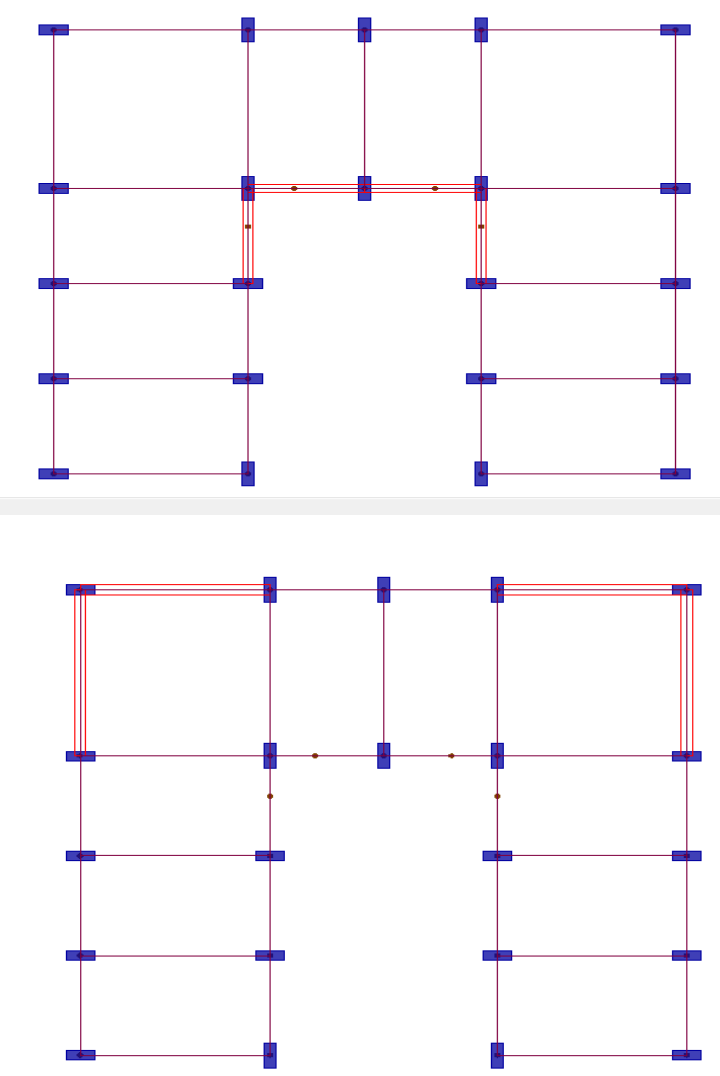

Fig-8: Re-entrant Corner Building with Inner and Outer Notches Strengthened with Shear Walls
Resultant roof drifts from response spectrum analysis for buildings strengthened with shear walls are shown in fig-10. It can be seen that building strengthened with shear walls at the inner notch experiences much lesser drifts compared to building strengthened with shear walls at the outer notch. Hence, strengthening the inner notch of the building is more effective in reducing the roof drifts compared to strengthening of outer notch of the building with shear walls.

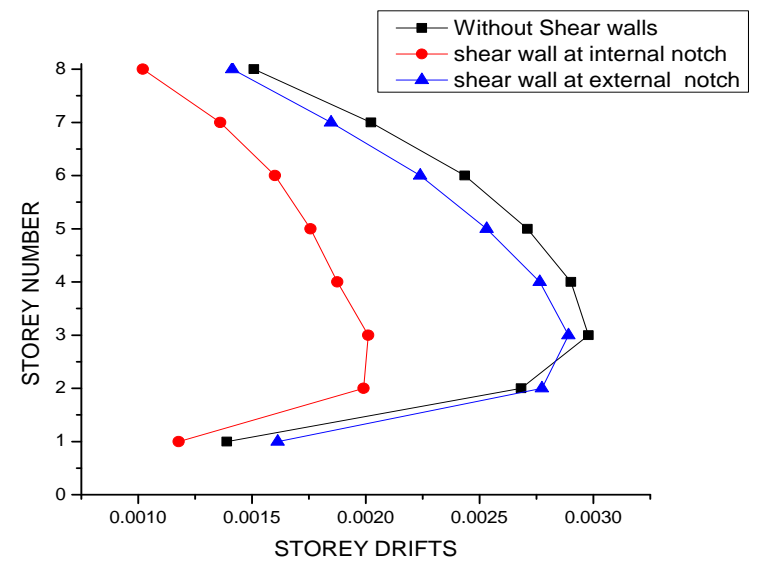

Fig-9: Roof Drifts for Re-entrant Corner Building with Inner and Outer Notches Strengthened with Shear Walls

Further, parametric study is carried out to determine the effect of stiffness of shear wall elements on the behavior of building in earthquake load. For this purpose, thickness of the shear wall is varied from $75 \mathrm{~mm}$ to $300 \mathrm{~mm}$. Results of response spectrum analysis in the form of storey drifts are shown in fig10. It can be seen that, increase in the thickness of the shear wall reduces the roof drift considerably.

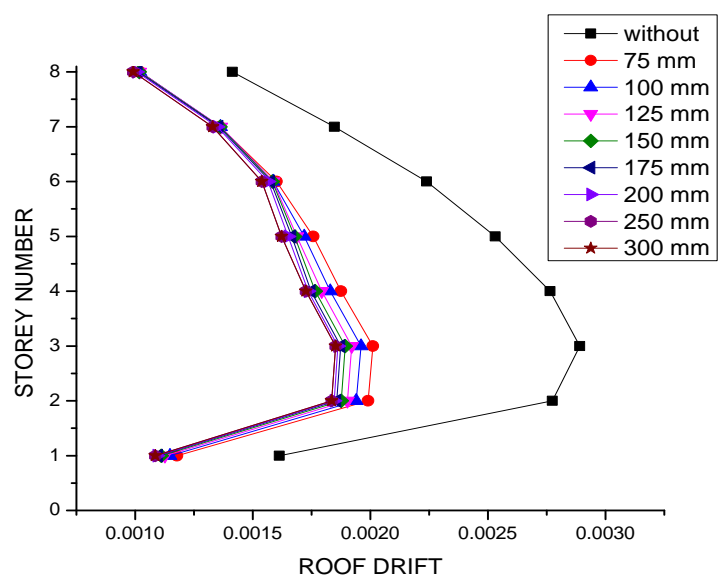

Fig-10: Effect of Shear Wall Thickness on Storey Drifts of Building 


\subsection{Strengthening of the Buildings with Bracings}

Fig-11 shows the configuration of bracings adopted for strengthening the building. X-type bracings are considered to strengthen the inner notch of the re-entrant corner of the irregular building. Bracings are made of the same grade of materials as that of other frame elements.

Results of analysis for buildings with and without bracings are shown in Fig-11. It is evident that buildings strengthened with bracings at the inner notch experiences much lesser drifts compared to un-braced buildings. It is also intended to study the effect of stiffness of bracings on the behavior of structure. For this sizes of bracings are varied from $150 \mathrm{~mm} \times 150 \mathrm{~mm}$ to $400 \mathrm{~mm} \times 400 \mathrm{~mm}$. It is seen that with increase in the stiffness of bracing elements storey drifts are significantly lesser.

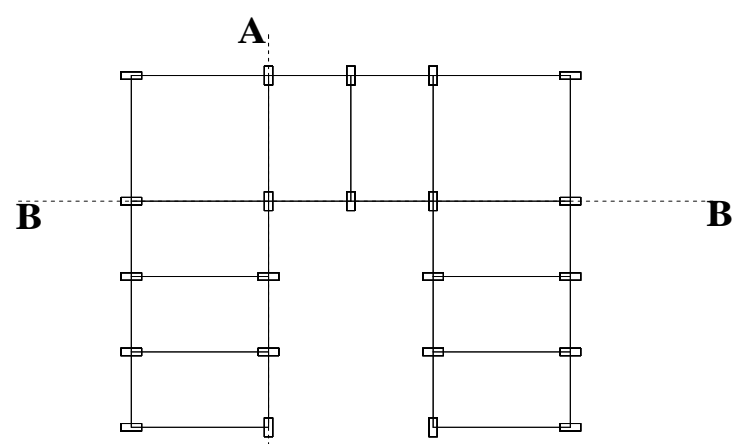

A

Building Plan

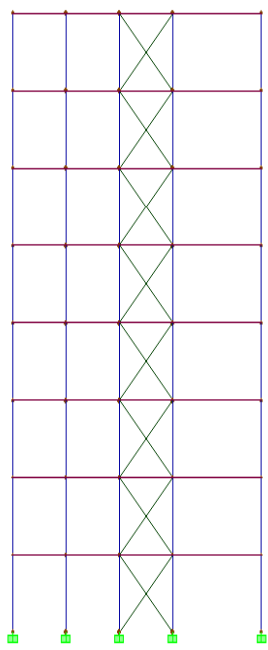

Section AA

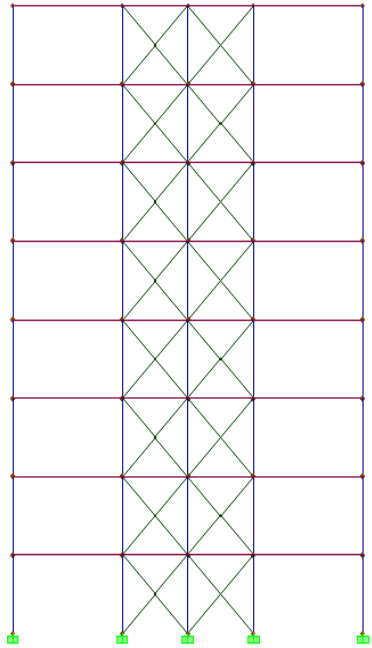

Section BB
Fig-11: Building Strengthened with bracings at the Inner Notch

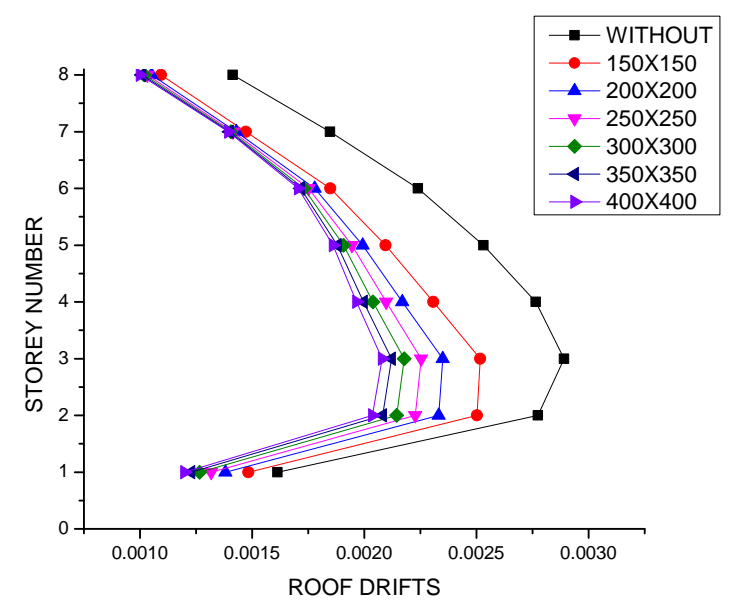

Fig-12: Storey Drifts for Different Sizes of Bracing Elements

\section{COMPARISION OF SHEAR WALLS AND BRACINGS}

It is clear from the results of analysis that introduction of bracings and shear walls improves the seismic performance of buildings with irregularities. Also, storey drifts decreases with increase in the stiffness of bracings and shear walls. For the purpose of cost comparison stiffness of the shear walls and bracings so chosen that the seismic performance in terms of storey drifts are similar with the incorporation of bracings and shear wall as in Fig-13.

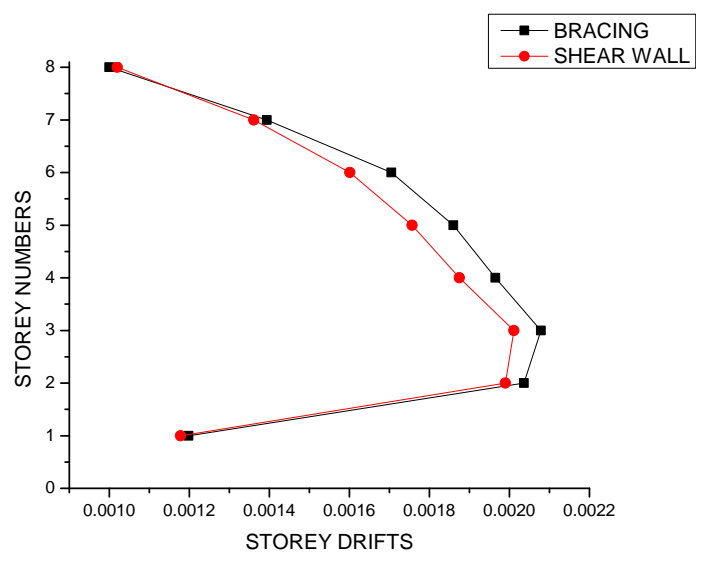

Fig-13: Similar Performance of Buildings with Shear wall and Bracings Chosen for Cost Comparison

At the point of similar performance, the total additional cost required for the strengthening of the building incurred by the incorporation of bracings and shear walls are worked out. For the purpose of estimation, expenses for materials (concrete and steel), form work, labour charges and other probable 
charges are included. Cost of materials and labors are adopted simulating the current standard practice of estimation.

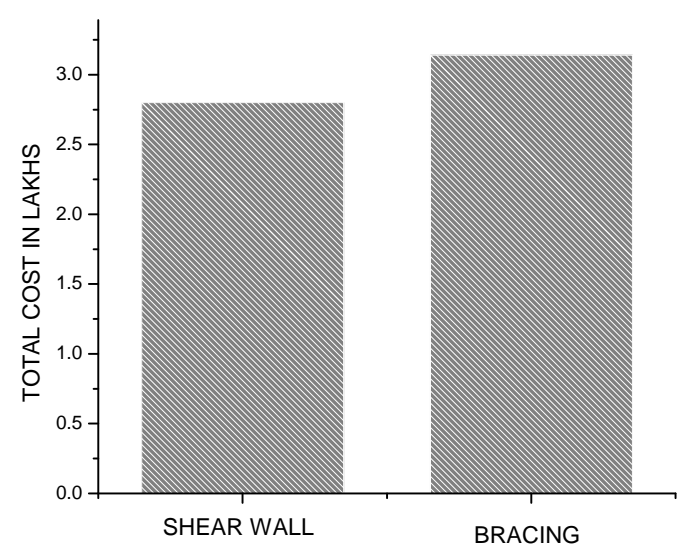

Fig-14: Cost Comparison between Bracing and Shear wall for a Similar Performance

From the cost comparison study, it can be seen that for a similar performance level incorporation of shear walls proves to be economical by about $18 \%$ compared to bracings (Fig14).

\section{CONCLUSIONS}

In the present study, an attempt is made to study the improvements in seismic performance of the buildings with re-entrant corners by the introduction of bracing and shear wall and to compare their relative efficiency.

- Regular buildings are found possess higher base shear capacity and experience much lower storey drifts compared to buildings with re-entrant corners.

- Status of hinge formation during pushover analysis indicates that members near the notch portion of the re-entrant corner are vulnerable for failure during earthquake and hence they need to be strengthened.

- Incorporation of bracings and shear walls improves the seismic performance of the building with reentrant corner and strengthening the inner notch is found to be much efficient compared to strengthening outer notch.

- Increase in the stiffness of shear walls and bracings decreases the storey drifts and their by improves the seismic performance of the structure.

- For a similar performance provision of shear walls prove to be more economical and efficient method of strengthening the building with re-entrant corner compared to incorporation of bracings.

\section{REFERENCES}

[1]. IS-1893- Part I: 2002, "Criteria for Earthquake Resistant Design of Structures", Bureau of Indian Standards, New Delhi.

[2]. Sujay Deshpande and Chandradhara G. P, Seismic Performance of R.C. Frames Irregular in Elevation from Pushover Analysis, $4^{\text {th }}$ Protect proceedings, 2013..

[3]. ETABS Nonlinear v9.6, Extended Three-dimensional Analysis of Building Systems, Computers and Structures Inc., Berkeley, California, USA, 1995.

[4]. Applied Technology Council (ATC 40) document, Seismic Evaluation and Retrofit of Concrete Buildings, Vol. 1, Report no. SSC 96-01, California, 1996

\section{BIOGRAPHIES}

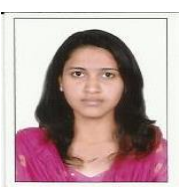

Divyashree $\mathrm{M}$ is a graduate in Civil Engineering from PESCE, Mandya. She has one year of experience with Traffic consultancy and currently pursuing her M.Tech degree in CAD of Structures from PES College of Engineering, Mandya.
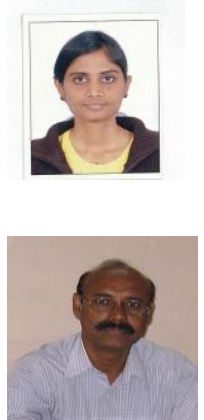

Bhavyashree B $\mathrm{N}$ is a graduate in Civil Engineering from PESCE, Mandya. She has a year of field experience. She is currently pursuing her M.Tech degree in CAD Structures from PES College of Engineering, Mandya.

Dr. Gopi Siddappa has graduation in Civil Engineering from Sri Jayachamarajendra college of Engineering, M.Tech from IIT Bombay and Ph.D from IIT Roorkie. He has over 27 years of teaching experience and is currently serving as Professor and Head of Department of Civil Engineering, PES College of Engineering, Mandya. 